\title{
Dhvar5 antimicrobial peptide (AMP) chemoselective covalent immobilization results on higher antiadherence effect than simple physical adsorption
}

\author{
Fabíola M.T.A. Costa ${ }^{\text {a, b, c }}$, Sílvia R. Maia ${ }^{\mathrm{d}}$, Paula A.C. Gomes ${ }^{\mathrm{d}, 1}$, \\ M. Cristina L. Martins a, b, e, * \\ a I3S, Instituto de Investigação e Inovação em Saúde, Universidade do Porto, Portugal \\ ${ }^{\mathrm{b}}$ INEB - Instituto de Engenharia Biomédica, Universidade do Porto, Rua do Campo Alegre, 823, 4150-180 Porto, Portugal \\ ${ }^{c}$ Universidade do Porto, Faculdade de Engenharia, Porto, Portugal \\ d CIQ-UP - Centro de Investigação em Química da Universidade do Porto, Departamento de Química e Bioquímica, Faculdade de Ciências, \\ Universidade do Porto, Porto, Portugal \\ e Universidade do Porto, Instituto de Ciências Biomédicas Abel Salazar, Porto, Portugal
}

\section{A R T I C L E I N F O}

Article history:

Received 25 November 2014

Received in revised form 8 February 2015

Accepted 13 February 2015

Available online

\section{Keywords:}

Antimicrobial peptides

Surface immobilization

Surface characterization

Bacterial adhesion

Chitosan

\begin{abstract}
A B S T R A C T
Bacterial colonization and subsequent biofilm formation is still one of the major problems associated with medical devices. Antimicrobial peptides (AMP) immobilization onto biomaterials surface is a promising strategy to avoid bacterial colonization. However, a correct peptide orientation and exposure from the surface is essential to maintain AMP antimicrobial activity.

This work aims to evaluate the effect of the immobilization on antibacterial activity of Dhvar5 (LLLFLLKKRKKRKY), an AMP with a head-to-tail amphipathicity. Dhvar5 was linked to thin chitosan coatings in i) a controlled orientation and exposure, testing covalent immobilization of its $\mathrm{N}$ - or C-terminus and using spacers with different lengths and flexibilities or in ii) a random orientation by physical adsorption. Chitosan coating was chosen due to its antimicrobial properties and readiness to be functionalized.

Surface characterization demonstrated the chemoselective immobilization of the peptide with different spacers in a similar concentration $\left(\sim 2 \mathrm{ng} / \mathrm{cm}^{2}\right)$.

Efficacy assays demonstrated that covalent immobilization of Dhvar5 exposing its cationic end, improves the chitosan coating antimicrobial effect by decreasing Methicillin-resistant Staphylococcus aureus (MRSA) colonization. This effect was enhanced when longer spacers were used independently of their flexibility. In opposite, immobilized Dhvar5 exposing its hydrophobic end has no effect on bacterial adhesion to chitosan, and when adsorbed in a random orientation even induces bacterial adhesion to chitosan coating.
\end{abstract}

() 2015 Elsevier Ltd. All rights reserved.

\section{Introduction}

Prevention of bacterial adhesion and biofilm formation on the surface of biomaterials remains a serious clinical issue yet unsolved. A number of different coating strategies, either for exposure or release of bactericidal substances (e.g., silver, quaternary ammonium

\footnotetext{
* Corresponding author. INEB - Instituto de Engenharia Biomédica, Rua do Campo Alegre 823, 4150-180 Porto, Portugal. Tel.: +351 22 6074982; fax: +351 22 6094567.

E-mail address: cmartins@ineb.up.pt (M.C.L. Martins).

${ }^{1}$ Present address: UCIBIO/REQUIMTE, Departamento de Química e Bioquímica, Faculdade de Ciências, Universidade do Porto, Porto, Portugal.
}

compounds, and classic antibiotics) have been tested along the past years [1-4]. However, the application of such coatings has been limited by associated side-effects, as cytotoxicity, hypersensitivity or the progressive alarming emergence of multi-resistant pathogens.

Antimicrobial peptides (AMP) are a class of promising antibiotic compounds with the major advantages being broad spectrum of activity, high efficiency at low concentrations, fast killing, good cytotoxic profile, and importantly, they rarely promote the rise of bacterial resistance $[5,6]$. For the majority of these peptides, the mode of action suggested is peptide insertion into bacterial membranes with subsequent cell death induction by, in some cases, cell lysis. Dhvar5 is a synthetic peptide, derived from the histatins family, which are produced by the salivary glands. Dhvar5 is a 
variant of Dh-5 (histatin 5 active domain, amino acids 11-24) with an $N$ - to $C$-terminal amphipathicity. It was firstly described as strongly active against Candida albicans, but has also a potent and broad antibacterial activity, even against methicillin-resistant Staphylococcus aureus (MRSA) [7-9]. The exact mechanism of action of soluble Dhvar5 is still not fully elucidated. Some cues emerged from the work by Amerongen and co-workers [10,11], where it was demonstrated that Dhvar5 binds to the membrane of yeast cells and induces leakage of intracellular content, but without permanent pore formation. The broad spectrum of Dhvar5, together with its safe cytotoxic profile, prompted its application on osteomyelitis prevention models. However, although the peptide revealed in vivo activity, it did not achieve the same treatment levels than gentamicin [12]. This situation may be associated with the pharmacokinetics challenges posed by AMP, as these are prone to undergo proteolytic degradation, self-aggregation and aggregation with plasma proteins. As previously summarized by us [13], covalent immobilization of AMP may offer the answer to such difficulties. Moreover, this strategy prevents the formation of a peptide concentration gradient from the implant surface, avoiding the side-effects associated with releasing therapies. Still, peptide immobilization is not a straightforward issue, as a number of different parameters should be taken into account, such as proper orientation ( $N$ - vs. C-terminal immobilization) and selection of an adequate spacer/linker (length and flexibility) for an optimal exposure.

\section{Materials and methods}

2.1. Dhvar5 synthesis and characterization

Pepide Dhvar5 (LLLFLLKKRKKRKY C-terminal amide) and its derivatives (Table 1) were produced by Fmoc/tBu solid-phase peptide synthesis methodologies assisted with microwave (MW) energy (Liberty 1 Microwave Peptide Synthesizer, CEM Corporation) $[14,15]$. Dhvar5-derived peptides were produced in order to introduce a terminal cysteine for subsequent immobilization. Different spacers were placed between the additional Cys and the bioactive sequence: 4-aminobutanoic (ABA) and 6-aminohexanoic (AHA) acids were used as flexible spacers of different length, whereas the dipeptide GlyGly (GG) was used as a spacer with comparable length to that of AHA, but lower flexibility, as peptide bonds do not allow the same conformational freedom as that of alkyl chains.

The crude peptides were purified by reverse-phase liquid chromatography and confirmed by High Performance Liquid Chromatography (HPLC) (Hitachi-Merck LaChrom Elite), Liquid Chromatography-Electrospray Ionization/Ion Trap Mass Spectrometry (LC-ESI/IT MS) (LCQ-DecaXP LC-MS system, ThermoFinnigan). Purified peptides used presented a purity level higher than $90 \%$.

\subsection{Dhvar5 surface immobilization}

\subsubsection{Substrates preparation}

Titanium substrates (Ti) were used to represent prosthesis surface and gold substrates (Au) were used due to their higher suitability for some of the surface characterization techniques used, such as ellipsometry and Infrared ReflectionAbsorption Spectroscopy Analysis (FT-IRRAS). Ti and Au $\left(1 \times 1 \mathrm{~cm}^{2}\right)$ were produced, cleaned and characterized according to references [16] and [17], respectively. Briefly, $\mathrm{TiO}_{2}$ films $(50 \mathrm{~nm})$ were deposited on silicon wafers (polished/etched, crystal orientation $\langle 100\rangle$, from AUREL Gmbh) by ion beam sputtering from a Ti cp target, in the presence of a mixed $\mathrm{Ar}-\mathrm{O}_{2}$ beam coming from the assist gun $(15.02 \%$ $\mathrm{O}_{2}$ in $\mathrm{Ar}$ ). For the Au substrates, chromium (5 nm) and gold $(25 \mathrm{~nm})$ layers were deposited by ion beam sputtering from chromium and gold targets ( $99.9 \%$ purity) on silicon wafers (AUREL, Gmbh). Chromium was used to improve gold adhesion to silicon. Both substrates were cleaned with "piranha" solution ( 7 parts of $\mathrm{H}_{2} \mathrm{SO}_{4}$ and

Table 1

Dhvar5 derived-peptides for immobilization.

\begin{tabular}{ll}
\hline Peptide & Sequence \\
\hline Dhvar5 & LLLFLLKKRKKRKY \\
Dhvar5-Ct_AHA_C & Dhvar5-(6-amino-hexanoyl)-Cys \\
C_AHA_Nt-Dhvar5 & Cys-(6-amino-hexanoyl)-Dhvar5 \\
C_ABA_Nt-Dhvar5 & Cys-(4-aminobutanoyl)-Dhvar5 \\
C_GG_Nt-Dhvar5 & Cys-GlyGly-Dhvar5 \\
\hline
\end{tabular}

3 parts of $30 \% \mathrm{H}_{2} \mathrm{O}_{2}$ ) for $90 \mathrm{~s}(\mathrm{Ti})$ and $5 \mathrm{~min}(\mathrm{Au})$ (caution: this solution reacts violently with many organic materials and should be handled with extreme care) and successively rinsed with ethanol, MilliQ water, ethanol and dried with a gentle stream of argon.

\subsubsection{Preparation of chitosan ultrathin films}

Chitosan ultrathin films were produced as previously described [18]. Briefly, commercial squid pen chitosan (France Chitine) was purified by the re-precipitation method [19] resulting on a molecular weight of $283,000-472,000$ with a deacetylation degree (DD\%) of $\sim 85 \%$. Chitosan ultrathin films (Ch) were prepared by spin coating (9000 rpm during $1 \mathrm{~min}$; Laurell Technologies Corporation, North Wales) a chitosan solution $(0.4 \%$ in acetic acid w/v) [20] on the center of the Au substrates. The ultrathin films produced were then neutralized with $0.1 \mathrm{~m} \mathrm{NaOH}$ and rinsed with MilliQ water. Each sample was dried with a gentle stream of argon and stored in plastic Petri dishes saturated with argon.

\subsubsection{Introduction of $\mathrm{SH}$ groups onto chitosan films}

Functionalization of chitosan thin films with $N$-acetyl cysteine (NAC), for introduction of SH groups, was previously optimized by Costa et al. [18], through employment of carbodiimide chemistry. Briefly, chitosan thin films were treated with a solution of $0.2 \mathrm{~m} 1$-Ethyl-3-[3-dimethylaminopropyl] carbodiimidehydrochloride) (EDC; Sigma-Aldrich), $0.05 \mathrm{~m} \mathrm{~N}$-hydroxysulfosuccimide (NHS; SigmaAldrich) and $25 \mathrm{~mm} \mathrm{NAC} \mathrm{(Merck),} \mathrm{in} 0.1 \mathrm{~m}$ ( $\mathrm{N}$-morpholino)ethanesulfonic acid (MES; Sigma-Aldrich) buffer at $\mathrm{pH}=6.5$, for $1 \mathrm{~h}$, at $37^{\circ} \mathrm{C}$ and $100 \mathrm{rpm}$. The modified films were then rinsed with MilliQ water and immersed $1 \mathrm{~min}$ on an ultrasound bath (Bandelin Sonorex Digitec Bath $35 \mathrm{kHz}$ ) and rinsed again with MilliQ water.

\subsubsection{Peptide immobilization}

Dhvar5 immobilization on chitosan thin films was obtained through disulfide bridge formation between the side chain thiol of the terminal cysteine of the peptide and sulfhydryl groups (SH) on pre-functionalized chitosan (Fig. 1).

Functionalized chitosan substrates were incubated with $1.5 \mathrm{mg} / \mathrm{ml}$ peptide solutions in $10 \mathrm{~mm}$ Tris $\mathrm{HCl} \mathrm{pH}=8.0$, under oxidative conditions (20\% dimethyl sulfoxide (DMSO)) for $18 \mathrm{~h}$ at $37^{\circ} \mathrm{C}$ and $120 \mathrm{rpm}$. A control Dhvar5-adsorbed sample was prepared by incubation with a non-functionalized chitosan film in the same reaction conditions.

\subsection{Surface characterization}

\subsubsection{FT-IRRAS}

Measurements were performed on a Perkin Elmer FTIR spectrophotometer, model 2000, coupled with a VeeMax II Accessory (PIKE) and a liquid-nitrogencooled MCT detector. In order to ensure that there was no water vapor adsorption, dry nitrogen was purged into the instrument for $5 \mathrm{~min}$ before and during measurement of each sample. For each substrate, a similar gold surface was used as a background. Incident light was p-polarized and spectra were collected using the $80^{\circ}$ grazing angle reflection mode. For each sample, 100 scans were collected with $4 \mathrm{~cm}^{-}$ ${ }^{1}$ resolution.

\subsubsection{Ellipsometry}

Ellipsometry measurements were performed using an imaging ellipsometer, model $\mathrm{EP}^{3}$, from Nanofilm Surface Analysis. This ellipsometer was operated in a polarizer-compensator-sample-analyzer (PCSA) mode (null ellipsometry). The light source was a solid-state laser with a wavelength of $532 \mathrm{~nm}$. The gold substrate refractive index $(\mathrm{n}=0.5837)$ and extinction coefficient $(\mathrm{k}=2.5113)$ were determined by using a delta and psi spectrum with an angle variation between $65^{\circ}$ and $71^{\circ}$. These measurements were made in four zones to correct for any instrument misalignment. The thickness of the chitosan films was determined considering $\mathrm{n}=1.54$ and $\mathrm{k}=0$, for the chitosan film [21]. Results are presented as the average of three measurements on each of two samples.

\subsubsection{Water contact angle measurements}

Water contact angle measurements were performed using the sessile drop method with a contact angle measuring system from Data Physics, model OCA 15, equipped with a video CCD-camera and SCA 20 software, as described at [17]. After deposition of $4 \mu \mathrm{l}$ drops of MilliQ water, images were taken every $2 \mathrm{~s}$ over $300 \mathrm{~s}$. Droplet profiles were fitted using Young-Laplace formula, to calculate the contact angle. The water contact angle of each substrate was calculated by extrapolating the time dependent curve to zero. Results are the average of three measurements on three independent samples.

\subsubsection{Peptide surface density determination}

The quantification of the immobilized peptides was performed through colorimetric reaction using 9,10-phenanthrenequinone (PHQ Fluka), that reacts with arginine forming a stable compound which gives out fluorescence upon excitation [22]. The protocol used was adapted from Ref. [23]. Substrates were sonicated $1 \mathrm{~h}$ in $0.1 \mathrm{M} \mathrm{HCl}(1 \mathrm{ml})$ in an ultrasound bath to dissolve the modified chitosan films. Then, $1 \mathrm{ml}$ of each sample solution was added to $3 \mathrm{ml}$ of $3.5 \mu \mathrm{M}$ PHQ in absolute ethanol, followed by the addition of $0.5 \mathrm{ml}$ of $2 \mathrm{~m} \mathrm{NaOH}$. The mixture 


\section{A. SH introduction into Chitosan films}<smiles>CC(=O)NC(CS)C(=O)O</smiles>

N-AcetylCysteine (NAC)<smiles>COC1C(O)CC(N)C(CO)OC1CO</smiles>

$\mathrm{H}$

Chitosan Film (Ch)

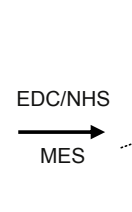

.

Chitosan-<smiles>CC(=O)NC(S)C(N)=O</smiles>

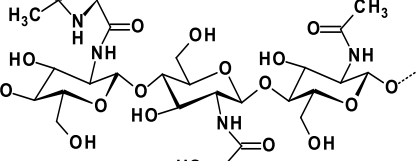

$\mathrm{OH}$ $>=0$ OH (Ch_NAC)

Symbols:

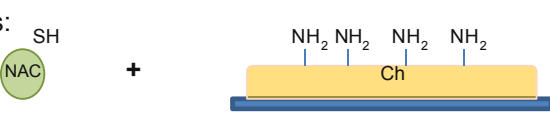

B1. Dhvar5 Peptide Spacer introduction
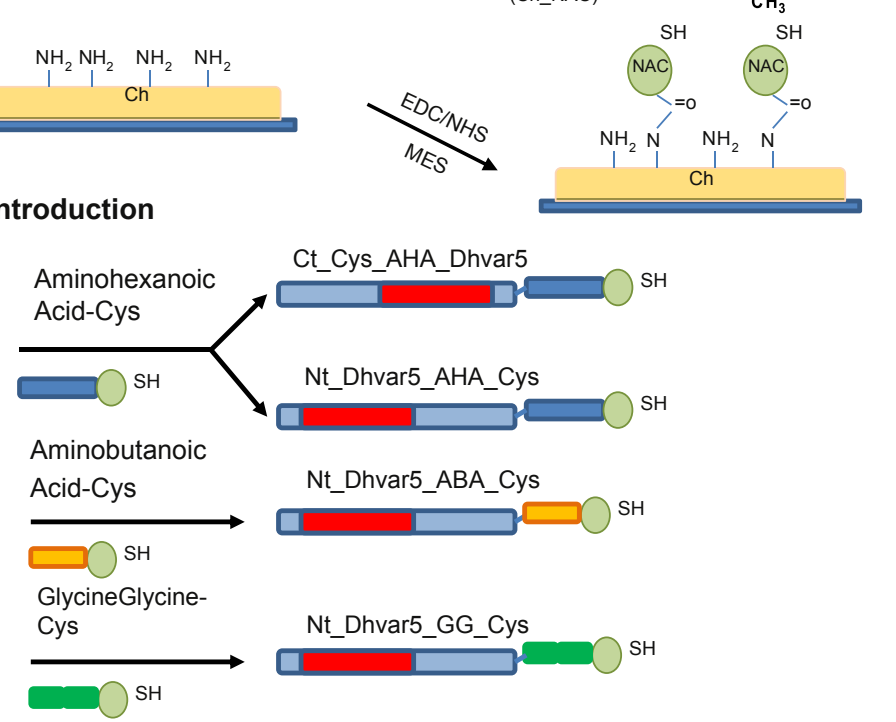

B2. Dhvar5 Peptide immobilization
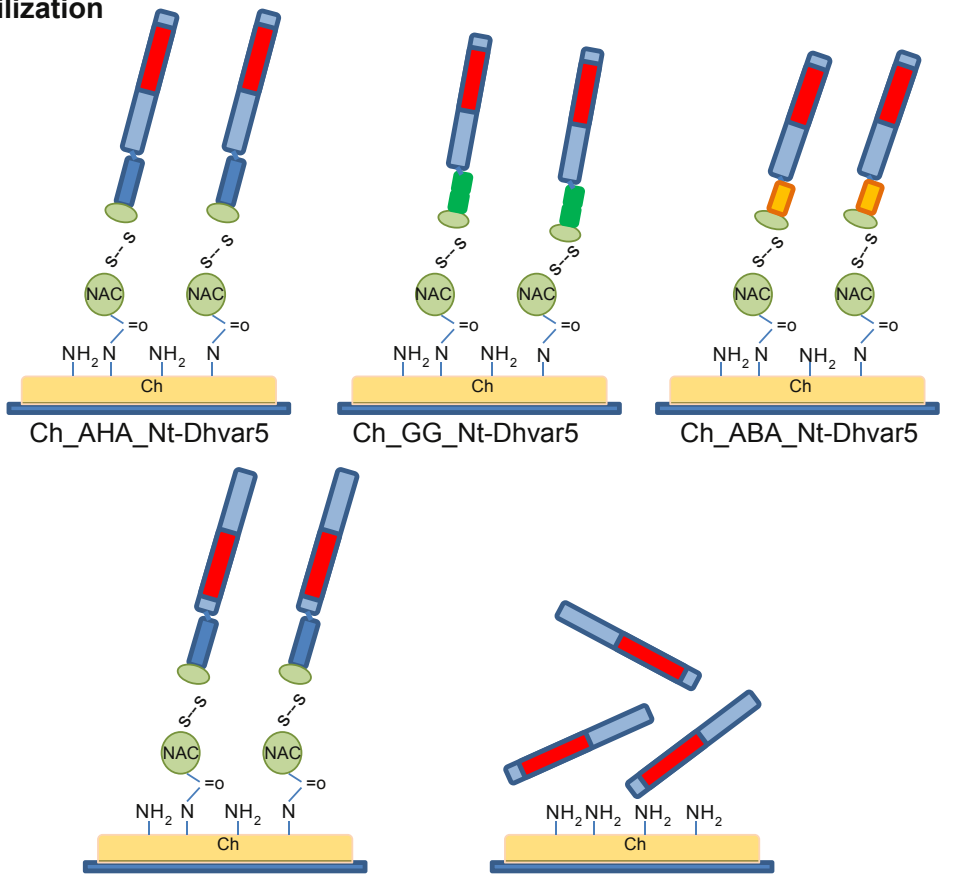

Ch_AHA_Ct-Dhvar5

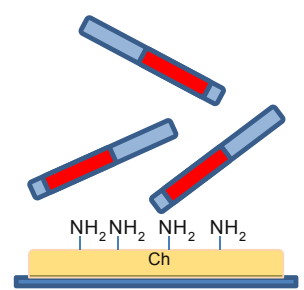

Ch Dhvar5 ads

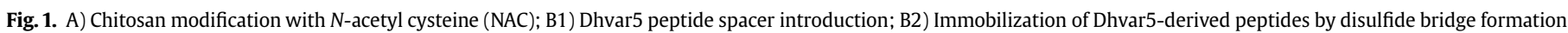
(a control surface, Ch Dhvar5 ads, was used where peptide was only adsorbed, not covalently bound).

was then incubated at $30^{\circ} \mathrm{C}$ for $3 \mathrm{~h}$. Finally, $2.25 \mathrm{ml}$ of $2.4 \mathrm{M} \mathrm{HCl}$ was added to stop the reaction. The fluorescence emission was measured using a fluorescence microplate reader (Biotek Synergy Mx Luminometer) using an excitation wavelength of $256 \mathrm{~nm}$, and detecting the emission at $380 \mathrm{~nm}$. The amount of Dhvar5 was calculated based on a calibration curve prepared with standard solutions of free L-arginine (Fluka) and free Dhvar5. Standard solutions of free Dhvar5 were adjusted by quantification at $280 \mathrm{~nm}$ in a Thermo Scientific NanoDrop ${ }^{\circledR} 1000$ spectrophotometer.

\subsection{Bacterial assays}

2.4.1. Bacterial strains, media and growth conditions

An MRSA strain of $S$. aureus was obtained from the American Type Culture Collection (ATCC 33591). Bacteria were firstly grown on Tryptic Soya Agar (TSA) (Merck) and then overnight on Tryptic Soya Broth (TSB) (Merck) at $37^{\circ} \mathrm{C}, 150 \mathrm{rpm}$. Bacterial suspensions were adjusted by measuring Optical Density $(600 \mathrm{~nm})$. Bacterial numbers were confirmed by a retrospective viable count. 
2.4.2. $M I C$

Minimal Inhibitory Concentration (MIC) was established with a modified broth microdilution method in Mueller Hinton Broth (MHB) [24].

\subsubsection{Surface antimicrobial activity characterization}

2.4.3.1. Sample preparation. All substrates were washed successively in $70 \%$ ethanol and sterile water, and then dried in sterile environment. Samples were then tape glued onto flat-bottomed 24-well cell suspension culture plates (Sarstedt, Ldt, Newton, USA)

2.4.3.2. Surface viability assay. Bacterial solution $\left(10^{7} \mathrm{CFU} / \mathrm{ml}\right)$ was added to each well and incubated at $37^{\circ} \mathrm{C}$ and $150 \mathrm{rpm}$ for $2 \mathrm{~h}$ in MHB. Surrounding wells were filled with sterilized deionized water, in order to avoid medium evaporation. Substrates were rinsed with $0.9 \% \mathrm{NaCl}$ sterile solution, and then stained with a combination dye of the LIVE/DEAD ${ }^{\mathbb{R}}$ Bacterial Viability Kit (Baclight ${ }^{\mathrm{TM}}$ ) for $15 \mathrm{~min}$ in the dark. Briefly, the kit contains two fluorescent dyes, Syto9 which stains all bacteria in green, and propidium iodide (PI) which can only crossover damaged cells membranes and gives red stained cells. Thus, because PI quenches the fluorescent emission of Syto9, it is assumed that green cells are alive whereas red cells are dead. Images were obtained with an inverted fluorescence microscope (Axiovert 200M, Zeiss, Germany). For quantifying the viability of adherent bacteria, eight fields on each of triplicate replicates were obtained with a 1000x magnification, corresponding to a net area of about $0.1181 \mathrm{~mm}^{2} /$ sample. The bacteria count was performed using the manual counting software included in Image software.

2.4.3.3. Long-term surface adhesion assay. Bacterial solution $\left(10^{7} \mathrm{CFU} / \mathrm{ml}\right)$ in $\mathrm{MHB}$ was added to each well containing the substrates. Cells were allowed to adhere for $2 \mathrm{~h}$ at $37^{\circ} \mathrm{C}$ and $120 \mathrm{rpm}$. Non-adherent bacteria were removed by washing three times with PBS at $120 \mathrm{rpm}$ for 5 min. Thereafter, samples were placed on a new 24well plate and incubated with fresh MHB for $24 \mathrm{~h}$ at $37^{\circ} \mathrm{C}$ and $120 \mathrm{rpm}$. Again, all unused wells were filled with sterilized deionized water, in order to avoid medium evaporation. At this point samples were rinsed with PBS, and fixed with $4 \%(\mathrm{w} / \mathrm{v})$ paraformaldehyde solution (Merck) for $20 \mathrm{~min}$. Samples were rinsed again with PBS and stained with VECTASHIELD ${ }^{\mathbb{R}}$ Mounting Medium with DAPI (4',6-diamidino-2phenylindole; Vector). DAPI bound to bacterial DNA is excited at about $360 \mathrm{~nm}$ and emits at about $460 \mathrm{~nm}$, resulting on blue fluorescence. Images were obtained with an inverted fluorescence microscope (Axiovert 200M, Zeiss, Germany). The quantification of adhered bacteria was performed as previously explained.

2.4.3.3.1. Growth inhibition assay. After the $24 \mathrm{~h}$ incubation period, supernatants were successively diluted and plated in triplicate on TSA. Before counting the colonies, plates were incubated at $37^{\circ} \mathrm{C}$ for $18 \mathrm{~h}$.

\subsection{Statistical analysis}

Statistical analysis was performed using One way ANOVA with Bonferroni multiple comparison post-hoc test. When Gaussian distribution was not confirmed, non-parametric test Kruskal-Wallis was applied using the Graphpad Prism program. Data is expressed as the mean \pm standard deviation (SD) and p values of $<0.05$ were considered significant.

\section{Results}

\subsection{Surface characterization}

Control and Dhvar5-modified surfaces were analyzed by ellipsometry, water contact angle measurement, FT-IRRAS and fluorimetric assays.

\subsubsection{Ellipsometry}

The spin-coating process resulted on chitosan ultrathin films of $9.3 \pm 1.0 \mathrm{~nm}$, which remained stable even after the reaction protocols, as there were no thickness changes between freshly made films and buffer-incubated films (Ch_b) (data not shown). Fig. 2A presents chitosan films thickness before and after surface modification.

The thickness of the chitosan films (Ch_b) was augmented after functionalization with NAC (Ch_NAC). The significant increase of the Ch_NAC film thickness after incubation with Dhvar5, supports the success of peptide attachment. Also, a similar increase was observed on Ch film after its incubation with Dhvar5 solution (Ch_Dhvar5_ads), suggesting peptide adsorption to the film. No significant difference was observed between the distinct orientations and spacers applied.

\subsubsection{Water optical contact angle (OCA) analysis}

Water optical contact angles of the control and modified $\mathrm{Ch}$ films are presented on Fig. 2B. The incorporation of NAC on Ch films increased significantly the hydrophilicity of the film decreasing the water contact angle from $65^{\circ}$ to $31^{\circ}$. After Dhvar 5 binding by its Cterminus (exposition of the more hydrophobic portion of the peptide) the water contact angle increases $\left(\theta_{\mathrm{w}}=67^{\circ}\right)$. On the other hand, all Nt-Dhvar5 immobilized samples showed a more hydrophilic behavior $\left(\theta_{\mathrm{w}}=54-56^{\circ}\right)$ than $C h \_b$, consistent with the immobilization of the peptide exposing its positively charged amino acids. No significant difference was observed between the samples with peptide immobilized by its N-terminus. Ch_Dhvar5_ads presented a water contact angle lower than Ch_b. Its value $\left(\theta_{\mathrm{w}}=60^{\circ}\right)$ is between the surfaces with peptide immobilized by its $\mathrm{N}$-terminus and its $\mathrm{C}$-terminus, suggesting some adsorbed peptide in a random orientation.

\subsubsection{FT-IRRAS}

FT-IRRAS results of the chitosan thin films, before and after immersion on buffer solution, showed that the films remained stable even after chemical procedures (Data not shown). FT-IRRAS analysis of Dhvar5 immobilized onto chitosan showed very similar spectra, therefore Fig. 3A depicts spectra of control Ch (Ch_b), and a representative spectrum of Dhvar5 immobilized onto Ch films.

Ch_b spectrum allowed the identification of characteristic absorption bands of chitosan, as previously described [19,20,25-27]. After Ch functionalization with NAC, an increase of amide I absorption band $\left(1654 \mathrm{~cm}^{-1}\right)$ was observed. This is consistent with the carbodiimide-mediated coupling reaction applied, leading to formation of an amide bond between free amine groups in $\mathrm{Ch}$ and the carboxylic groups of NAC. Subsequent covalent immobilization of Dhvar5-derived peptides also implies an increase of amide I band, characteristic of peptides/proteins. To assess Dhvar5 immobilization, a peak height ratio (amide I peak height $\left(1654 \mathrm{~cm}^{-1}\right) / \mathrm{C}-\mathrm{O}-\mathrm{C}$ glucopyranose peak height $\left(1083 \mathrm{~cm}^{-1}\right)$ ) was calculated (Fig. $3 \mathrm{~B}$ ). As expected, the aforementioned ratio increased in the following order: Ch_b $<$ Ch_NAC $<$ Ch films with covalently bound Dhvar5. All samples with covalently immobilized peptide presented a nearly identical ratio that was around 1.5 fold higher than Ch_NAC and about 3 fold higher than Ch_Dhvar5_ads. Altogether, FT-IRRAS results clearly support the success of the covalent immobilization chemistry applied.

\subsubsection{Peptide quantification}

The average surface peptide density is presented on Table 2. The average surface density was similar between all $\mathrm{Ch}$ films with covalently bound Dhvar5 $\left(\sim 2.0 \mathrm{ng} / \mathrm{mm}^{2}\right)$. The film with adsorbed Dhvar5 (Ch_Dhvar5_ads), although with a higher density (4.0 ng/ $\mathrm{mm}^{2}$ ), was not significantly different from the covalently immobilized samples, with the exception of Ch_AHA_Nt-Dhvar5.

\subsection{Antimicrobial activity characterization}

Dhvar5 antimicrobial activity was firstly assessed in solution, by an adaptation of the microtiter broth dilution method proposed elsewhere [24,28]. S. aureus strain used presented a MIC of $0.5 \mu \mathrm{g} /$ $\mathrm{ml}$.

\subsubsection{Viability assays}

Viability of bacteria attached to the surfaces was evaluated using LIVE/DEAD ${ }^{\circledR}$ Bacterial Viability Kit (Baclight ${ }^{\mathrm{TM}}$ ). Fig. 4A presents the average number of bacteria per $\mathrm{mm}^{2}$ of each surface sample, after $2 \mathrm{~h}$ incubation at $37^{\circ} \mathrm{C}$. 
A

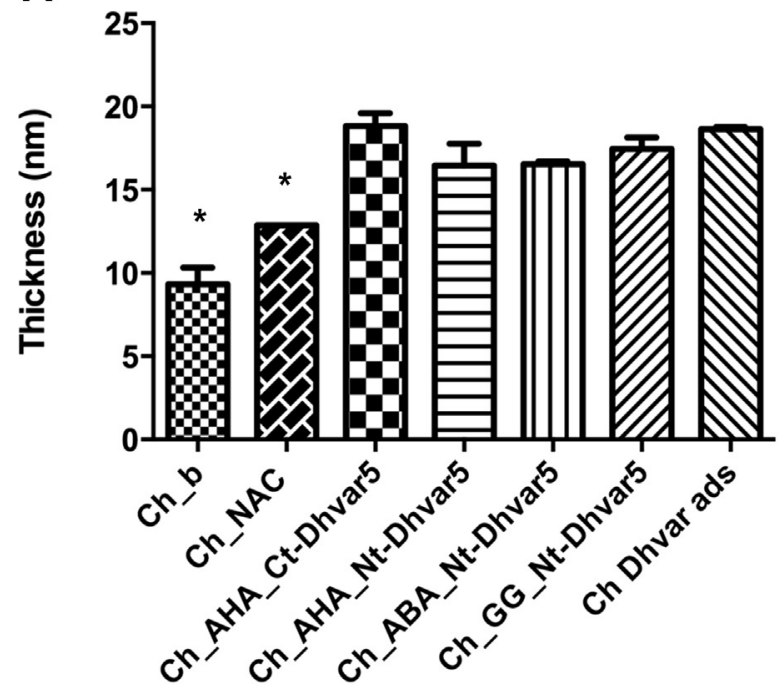

B

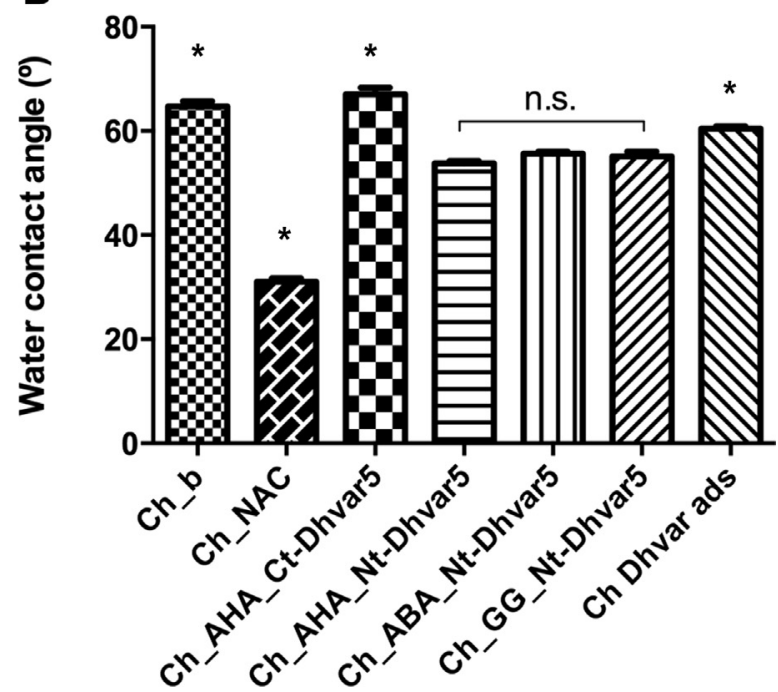

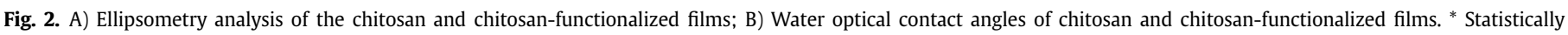
different from all other samples ( $p<0.05$ ) (non-parametric Kruskal-Wallis test).

A

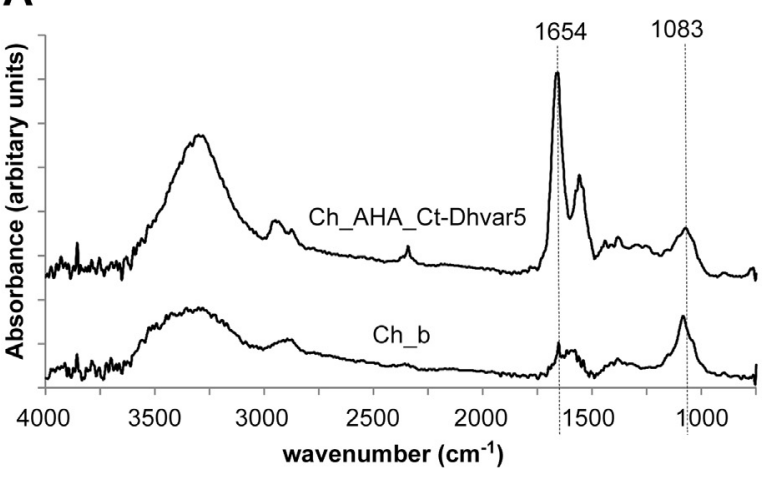

B

\begin{tabular}{lc}
\hline Ch modified films & $\begin{array}{c}\text { Peak height } \\
\text { ratio }\end{array}$ \\
\hline Ch Dhvar5 ads & 1.7 \\
Ch_NAC & 3.8 \\
Ch_AHA_Ct-Dhvar5 & 5.2 \\
Ch_AHA_Nt-Dhvar5 & 5.4 \\
Ch_ABA_Nt-Dhvar5 & 5.4 \\
Ch_GG_Nt-Dhvar5 & 5.9 \\
Ch_b & 0.62 \\
\hline
\end{tabular}

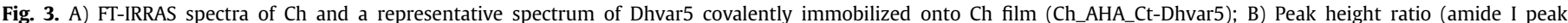
$\left(1654 \mathrm{~cm}^{-1}\right) / \mathrm{C}-\mathrm{O}-\mathrm{C}$ peak $\left.\left(1083 \mathrm{~cm}^{-1}\right)\right)$ of modified $\mathrm{Ch}$ films.

Regarding total adhered bacteria, control samples ( $\mathrm{Ti}$ and $\mathrm{Au}$ ) exhibited high values, whereas $\mathrm{Ch}$ coating ( $\mathrm{Ch}$-b) promoted a reduction of around $40 \%$ (47\% comparing to Ti and 39\% comparing to $\mathrm{Au}$ ). This result was expected, since we previously demonstrated the antimicrobial properties of this chitosan ultrathin films [18]. Remarkably, films with adsorbed peptide (Ch_Dhvar5_ads) did not significantly differ from Ti neither from $\mathrm{Au}$ in total adhered bacteria, demonstrating that the adsorbed Dhvar5 induced bacterial adhesion to chitosan film. In opposite, samples with peptide covalently immobilized through its $N$-terminus exhibited a marked

Table 2

Dhvar5 surface density evaluation, based on fluorescent intensities.

\begin{tabular}{ll}
\hline Ch modified films & Dhvar5 surface density $\left(\mathrm{ng} / \mathrm{mm}^{2}\right)$ \\
\hline Ch_AHA_Ct-Dhvar5 & $2.4 \pm 0.7$ \\
Ch_AHA_Nt-Dhvar5 & $1.5 \pm 0.0^{\mathrm{a}}$ \\
Ch_ABA_Nt-Dhvar5 & $2.1 \pm 0.4$ \\
Ch_GG_Nt-Dhvar5 & $1.8 \pm 0.2$ \\
Ch Dhvar5 ads & $4.0 \pm 0.9^{\mathrm{a}}$ \\
\hline
\end{tabular}

a Statistically different from each other $(\mathrm{p}<0.05)$ (non-parametric Kruskal-Wallis test). decrease as compared to $\mathrm{Ti}$, reaching an $\sim 80 \%$ reduction when a longer spacer was used (Ch_AHA_Nt-Dhvar5 and Ch_GG_NtDhvar5) $(\mathrm{p}<0.05)$. These two Dhvar-bearing surfaces did not significantly differ from each other and revealed an anti-adherence behavior $\sim 62 \%$ plus effective than that of Ch_b. In turn, C-terminus immobilization of Dhvar5 did not significantly differ from control Ch_b film regarding anti-adherence properties. Hence, these results clearly show that, amongst all surfaces analyzed, those coated with Ch covalently bound to Dhvar5 through a longer spacer and exposing the more hydrophilic and cationic end of the peptide were the best suited to avoid bacterial colonization.

It was also observed that most of the adhered bacteria were not dead, in all surfaces. Still, $N$-terminally immobilized Dhvar5 exhibited a total number of live adhered bacteria two-fold lower than Ch_b samples and five-fold lower than Ti substrates.

\subsubsection{Long-term anti-adherence assays}

The objective of this assay was to verify if the live adhered bacteria would proliferate if time and proper nutritional conditions were given. For that, surfaces with the $2 \mathrm{~h}$ incubation resulting adherent bacteria were immersed on fresh medium for $24 \mathrm{~h}$. The results are presented in Fig. 4B. 
A

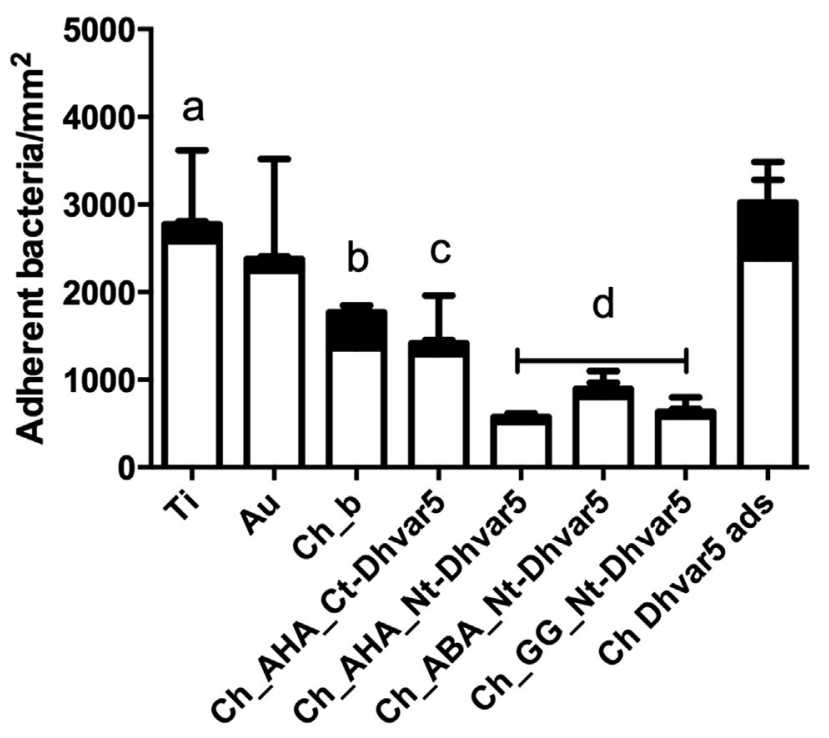

B

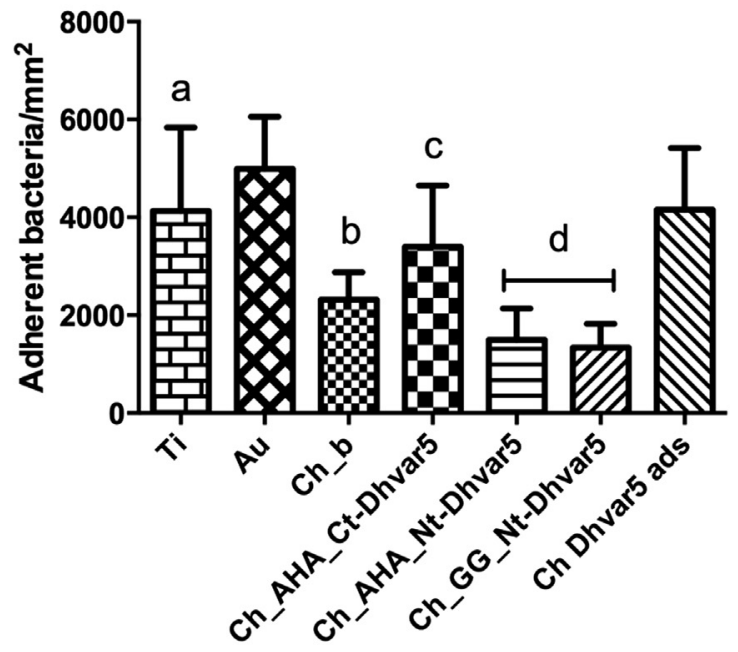

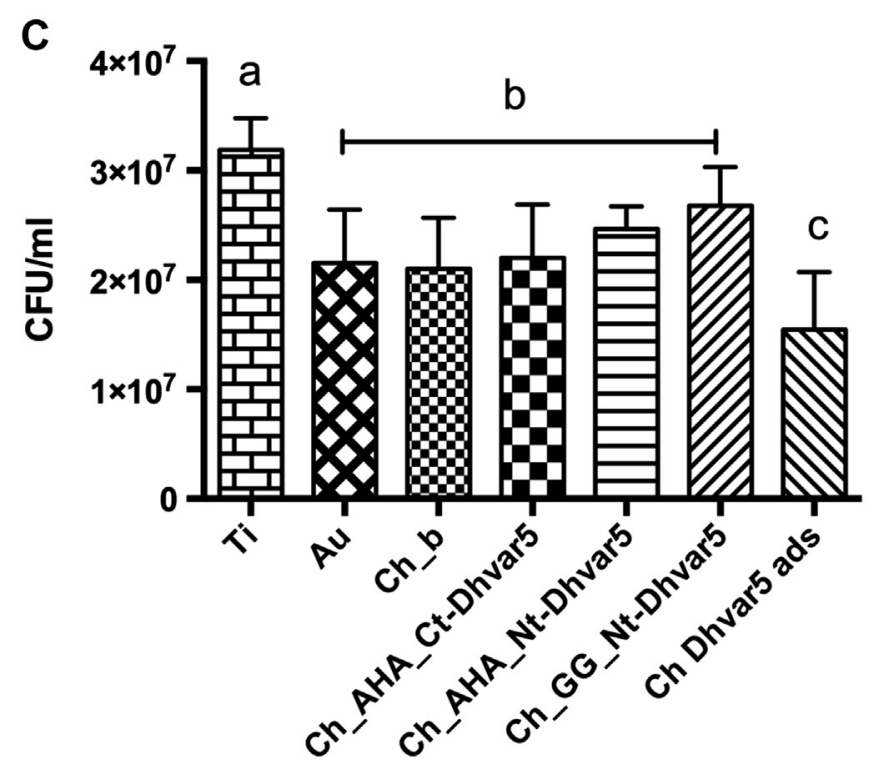

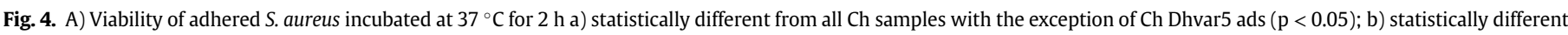

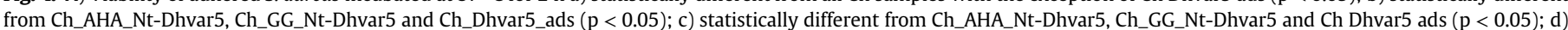

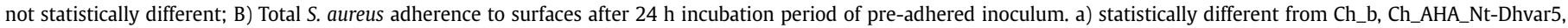

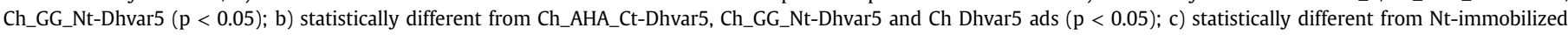

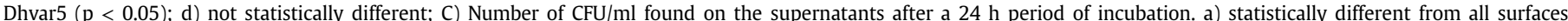

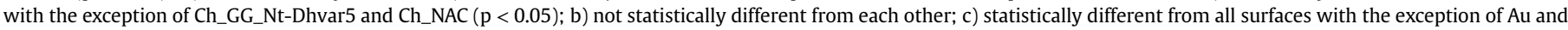
Ch_b (One-Way ANOVA analysis).

Ti and Au exhibited a similar and high number of adhered bacteria that allowed an increase of the number of adherent bacteria on their surfaces regarding to the initial adherent bacteria $\left(\sim 2000\right.$ bacteria $\left./ \mathrm{mm}^{2}\right)$. Similar results were obtained for Ch_Dhvar5_ads. Ch films with immobilized Dhvar5 by its $N$-terminus presented the lowest bacterial adhesion levels ( $70 \%$ and $\sim 40 \%$ reduction as compared to $\mathrm{Ti}$ and $\mathrm{Ch} \_\mathrm{b}$, respectively). However, these surfaces were not able to completely avoid bacterial proliferation, since there is an increase of the adherent bacteria during incubation ( $24 \mathrm{~h})$. Ch coating and Ch_Dhvar5_ads were the surfaces that allowed the lowest proliferation. However, the number of adherent bacteria on these surfaces was very high.

Growth inhibition assays of the supernatants of the long-term incubation experiments are depicted on Fig. 4C.
Ti substrates presented the highest value of $\mathrm{CFU} / \mathrm{ml}$, which adding to the high amount of adhered bacteria at the substrate (see Fig. 4B), confirms its lack of antimicrobial activity. No significant difference was found between $\mathrm{Au}, \mathrm{Ch} \_\mathrm{b}$ and surfaces with immobilized Dhvar5. Ch_Dhvar5_ads was the substrate that contributed to the lowest number of $\mathrm{CFU} / \mathrm{ml}$ in the supernatant, which may be related to elution of the peptide into the MHB.

\section{Discussion}

Dhvar5 presented a promising MIC of $0.5 \mu \mathrm{g} / \mathrm{ml}$ against a methicillin-resistant $S$. aureus (MRSA) that is lower than the reported elsewhere $[8,9,12,29,30]$. However, direct comparison of such values is very difficult, as a result of the lack of universal 
standardized methods to assess AMP activity, besides the use of different $S$. aureus strains. We chose to use the standard conditions already proposed by Wiegand et al., [24].

In this study, Dhvar5 was covalently immobilized onto chitosan thin films in order to evaluate if this strategy is able to prevent bacterial adhesion in a sustainable way. Different immobilization parameters were tested, to assess the immobilization profile that would most contribute to such goal. Different surface characterization techniques - ellipsometry, FT-IRRAS, OCA and fluorimetric peptide quantification - confirmed the production of stable chitosan thin films, with a chemoselective covalent immobilization of the peptide in different orientations. The stability of chitosan films was confirmed using ellipsometry and FT-IRRAS. Ellipsometry measurements demonstrated a clear thickness increase of Dhvar5modified chitosan films comparing to controls (Ch_b and Ch_NAC). However, such analysis alone did not prove the covalent immobilization of the peptide, nor its proper orientation. Demonstration of the covalent immobilization of the peptide was suggested by FTIRRAS analysis, namely through comparison of the amide I peak height $\left(1654 \mathrm{~cm}^{-1}\right) / \mathrm{C}-\mathrm{O}-\mathrm{C}$ glucopiranose peak height $\left(1083 \mathrm{~cm}^{-1}\right)$ ratio, that was clearly increased when Dhvar5 was covalently bound to chitosan, as compared to NAC-functionalized chitosan and Ch_Dhvar5_ads. The peak height ratio was also increased on Ch_Dhvar5_ads comparing to unmodified chitosan. In this case the amide I peak is related to the peptide bonds of the adsorbed peptide and not to the covalent immobilization amide bond, noticeable by a lower peak ratio increase. Regarding the specificity of the immobilization orientation, useful information was brought by OCA measurements. NAC-functionalized chitosan films became significantly more hydrophobic (2.1 fold) upon immobilization of Dhvar5 through its $C$-terminus (Dhvar5 hydrophobic portion exposed) and only 1.7 fold more hydrophobic when immobilization was made through the $N$-terminus of the peptide (cationic residues exposed). OCA also enabled the confirmation of Dhvar5 adsorption, by the small but significant contact angle shift in Ch_Dhvar5_ads comparing to Ch_b. This shift may be the result of multiple orientations of the adsorbed peptide, rather than one preferential orientation established by the covalently immobilization process, as also proposed by Chen et al., [31].

Antimicrobial activity of control and peptide-bearing surfaces was assessed through two levels of stringency: adhesion and viability after $2 \mathrm{~h}$ of incubation, and after long-term incubation (24 h). All Dhvar5 modified surfaces presented a significant bacterial adhesion reduction when compared to Ti and chitosan with the exception of Dhvar5 adsorbed sample. Interestingly, the adsorbed strategy exhibited an amount of adhered bacteria quite similar to controls ( $\mathrm{Ti}$ and $\mathrm{Au}$ ). Also, Williams et al. [32], reported a study where contact lenses with adsorbed lactoferrin exhibited a high adherence of Pseudomonas aeruginosa.

Covalently immobilized Dhvar5 resulted in different profiles depending on the exposed peptide terminus. C-terminally immobilized Dhvar5 maintained the level of bacterial adhesion of $\mathrm{Ch}$ _b after $2 \mathrm{~h}$ incubation, but had a higher number of adhered bacteria on $24 \mathrm{~h}$ incubation. This suggests that in a long-term incubation, exposure of the hydrophobic portion of the peptide masks Ch_b intrinsic activity, resulting in unwanted adhesion. In opposite, $\mathrm{N}$ terminally immobilized Dhvar5 have the lowest bacterial adhesion in both incubation periods. However, the viability of adhered bacteria was high independent of the terminus used for immobilization, suggesting that we have a stronger anti-adherence rather than antimicrobial effect. Confronting the levels of surface-adhered bacteria with those of free bacteria at the supernatants, we came to the conclusion that, in the absence of surface coating (i.e., on the Ti control), a high number of bacteria is found both at the surface and in solution. In turn, all the chitosan-coated surfaces, with or without further modification, presented similar amounts of free bacteria at the supernatants, which do not correlate with the respective lower amount of surface-adhered bacteria. Nevertheless, the high amount of bacteria at the supernatant may be the result of the proliferation of planktonic bacteria that were never in contact with the surfaces.

The lowest CFU count found in supernatants regards the surface with adsorbed Dhvar5, presumably as the result of peptide elution to the bulk phase. However, this result loses relevance given the $\sim 70 \%$ increase of adhered bacteria in this sample, as compared with best performing Dhvar5-grafted surfaces.

Recently, Chen et al. [33], reported that melimine, a 28mer peptide with an $\mathrm{N}$-terminus hydrophobic domain and cationic $\mathrm{C}$ terminus, presented higher antimicrobial activity with a clear antiadherence effect when immobilized through its $\mathrm{N}$-terminus, exposing the cationic domain away from the substrate. This comes in accordance with our results. In contrast to these results, Hilpert et al. [34], found that immobilized AMP exposing their hydrophobic termini exhibited higher bactericidal activity. They stated that the hydrophobic domain should be free to be able to interact with the lipophilic portion of the bacterial membrane. However, they used a peptide library that did not include peptides with a clear 'head-totail' amphipathicity, but rather a conformation-dependent amphipathicity. Indeed, they hypothesized that a concentration of cationic residues on the exposed terminus could similarly lead to high antimicrobial activity.

Within the $N$-terminal immobilizations, differential antiadherence effects were obtained depending on the length of the spacer applied. It was clear that longer spacer (AHA or GG) had better results than shorter ( $A B A)$ spacers. The two longer spacers had very similar results, suggesting that, with this particular peptide, spacer length is more important than spacer flexibility. Bagheri et al. [35], demonstrated the importance of a longer spacer on AMP antimicrobial activity. Nevertheless, reports diverge in their general conclusion about the specific characteristics of the applied spacer, suggesting that it may be peptide-dependent. More recently, Bagheri et al. [36], tried to assess whether the mechanism of action of soluble AMP could be relevant for the correct configuration of immobilization. To that end, those authors chose different AMP with distinct putative mechanisms of action, and tested them after different tethering approaches. Overall, they concluded that peptides with intracellular targets lose activity upon covalent immobilization whereas the behavior of membranepermeabilizing peptides depend on their amphipathicity distribution. Thus, the activity of covalently immobilized peptides whose amphipathicity is conformation-dependent (as the KLAL model peptide) is not significantly affected by the orientation of immobilization. On the other hand, peptides with sequence-based amphipathicity (as melittin) should be covalently immobilized through the position farthest away from the hydrophobic domain. In other words, these authors concluded that membrane-active AMP should have their hydrophobic domain exposed in order to insert into the bacterial lipid bilayer. As reported by Ruissen et al., [10], Dhvar5 can cause cytoplasmic membrane depolarization suggestive of membranolytic activity, but not through permanent pore formation. This mechanism of action, in addition to the sequence-based amphipathicity of Dhvar5, would suggest that its optimal immobilization position should be through the $C$-terminus, as this would result on greater exposition of the hydrophobic domain. However, this does not correlate with our results, nor with the aforementioned report by Chen et al., in Ref. [33]. Our results demonstrated that immobilized Dhvar5 lost part of their antimicrobial effect against $S$. aureus independently of their immobilization orientation. Nevertheless, immobilization by the $\mathrm{N}$-terminus, exposing the cationic part, demonstrates a high anti-adhesive 
effect. These apparently contradictory findings highlight the little that is known about the mechanisms of action of AMP, mostly immobilized ones, suggesting once again that soluble and immobilized AMP may not share the same mechanism of action, as recently proposed by Kizhakkedathu et al., [37]. Therefore, each individual AMP must be carefully studied regarding main parameters of immobilization towards creation of effective antifouling coatings, as herein reported for Dhvar5.

\section{Conclusions}

Dhvar 5 covalently immobilized onto a chitosan thin coating by the $N$-terminus (exposing the cationic end), improves the antimicrobial effect of the coating by decreasing $S$. aureus colonization. This effect was enhanced when longer spacers were used independently of its flexibility. In opposition, Dhvar5 covalent immobilization by the $C$-terminus did not change bacterial adhesion to chitosan and Dhvar5 physically adsorbed even induced bacterial adhesion to chitosan coatings.

This work demonstrated that, after surface immobilization, the exposition of the cationic end of this amphipathic peptide (Dhvar5) is fundamental to create antimicrobial surfaces by avoiding bacterial colonization.

\section{Acknowledgments}

This work was financed by FEDER funds through the Programa Operacional Factores de Competitividade (COMPETE) and by Portuguese funds through FCT (Fundação para a Ciência e a Tecnologia) in the framework of the projects: PTDC/CTM/101484/2008; PEst-C/ SAU/LA0002/2013; Pest-C/QUI/UI0081/2013. Fabíola Costa acknowledges FCT for the PhD grant SFRH/BD/72471/2010.

\section{References}

[1] Norowski Jr PA, Bumgardner JD. Biomaterial and antibiotic strategies for periimplantitis: a review. J Biomed Mater Res B Appl Biomater 2009;88:530-43.

[2] Bazaka K, Jacob MV, Crawford RJ, Ivanova EP. Efficient surface modification of biomaterial to prevent biofilm formation and the attachment of microorganisms. Appl Microbiol Biotechnol 2012;95:299-311.

[3] Glinel K, Thebault P, Humblot V, Pradier CM, Jouenne T. Antibacterial surfaces developed from bio-inspired approaches. Acta Biomater 2012;8:1670-84.

[4] Banerjee I, Pangule RC, Kane RS. Antifouling coatings: recent developments in the design of surfaces that prevent fouling by proteins, bacteria, and marine organisms. Adv Mater 2011;23:690-718.

[5] Zasloff M. Antimicrobial peptides of multicellular organisms. Nature 2002;415:389-95.

[6] Seo MD, Won HS, Kim JH, Mishig-Ochir T, Lee BJ. Antimicrobial peptides for therapeutic applications: a review. Molecules 2012;17:12276-86.

[7] Ruissen AL, Groenink J, Helmerhorst EJ, Walgreen-Weterings E, Van't Hof W, Veerman EC, et al. Effects of histatin 5 and derived peptides on Candida albicans. Biochem J 2001;356:361-8.

[8] Stallmann HP, Faber C, Bronckers AL, de Blieck-Hogervorst JM, Brouwer CP, Amerongen AV, et al. Histatin and lactoferrin derived peptides: antimicrobial properties and effects on mammalian cells. Peptides 2005;26:2355-9.

[9] Lyaruu DM, Van T, Hof W, Veerman EC, Burger EH, Amerongen AVV. Antibacterial activity of human saliva histatin analogues against methicillinresistant S-aureus (MRSA). J Dent Res 2000;79:227.

[10] Ruissen AL, Groenink J, Van't Hof W, Walgreen-Weterings E, van Marle J, van Veen HA, et al. Histatin 5 and derivatives. Their localization and effects on the ultra-structural level. Peptides 2002;23:1391-9.

[11] den Hertog AL, Sang HWWF, Kraayenhof R, Bolscher JGM, Van't Hof W, Veerman ECI, et al. Interactions of histatin 5 and histatin 5-derived peptides with liposome membranes: surface effects, translocation and permeabilization. Biochem J 2004;379:665-72.

[12] Faber C, Hoogendoorn RJ, Stallmann HP, Lyaruu DM, van Nieuw Amerongen A Wuisman PI, et al. In vivo comparison of Dhvar-5 and gentamicin in an MRSA osteomyelitis prevention model. J Antimicrob Chemother 2004;54:1078-84.
[13] Costa F, Carvalho IF, Montelaro RC, Gomes P, Martins MC. Covalent immobilization of antimicrobial peptides (AMPs) onto biomaterial surfaces. Acta Biomater 2011;7:1431-40.

[14] Fields GB, Noble RL. Solid phase peptide synthesis utilizing 9fluorenylmethoxycarbonyl amino acids. Int J Pept Protein Res 1990;35: $161-214$.

[15] Collins JM, Leadbeater NE. Microwave energy: a versatile tool for the biosciences. Org Biomol Chem 2007;5:1141-50.

[16] Sousa SR, Moradas-Ferreira P, Saramago B, Melo LV, Barbosa MA. Human serum albumin adsorption on $\mathrm{TiO}_{2}$ from single protein solutions and from plasma. Langmuir 2004;20:9745-54.

[17] Martins MC, Ratner BD, Barbosa MA. Protein adsorption on mixtures of hydroxyl- and methyl-terminated alkanethiols self-assembled monolayers. J Biomed Mater Res A 2003;67:158-71.

[18] Costa F, Maia S, Gomes J, Gomes P, Martins MC. Characterization of hLF1-11 immobilization onto chitosan ultrathin films, and its effects on antimicrobial activity. Acta Biomater 2014;10:3513-21.

[19] Oliveira JR, Martins MCL, Mafra L, Comes P. Synthesis of an O-alkynyl-chitosan and its chemoselective conjugation with a PEG-like amino-azide through click chemistry. Carbohyd Polym 2012;87:240-9.

[20] Nogueira F, Goncalves IC, Martins MC. Effect of gastric environment on helicobacter pylori adhesion to a mucoadhesive polymer. Acta Biomater 2013;9: $5208-15$.

[21] Lundin M, Macakova L, Dedinaite A, Claesson P. Interactions between chitosan and SDS at a low-charged silica substrate compared to interactions in the bulk-the effect of ionic strength. Langmuir 2008;24:3814-27.

[22] Smith RE, MacQuarrie R. A sensitive fluorometric method for the determination of arginine using 9,10-phenanthrenequinone. Anal Biochem 1978;90: 246-55.

23] Kazemzadeh-Narbat M, Kindrachuk J, Duan K, Jenssen H, Hancock RE Wang R. Antimicrobial peptides on calcium phosphate-coated titanium for the prevention of implant-associated infections. Biomaterials 2010;31: 9519-26.

24] Wiegand I, Hilpert K, Hancock RE. Agar and broth dilution methods to determine the minimal inhibitory concentration (MIC) of antimicrobial substances. Nat Protoc 2008;3:163-75.

[25] Osman Z, Arof AK. FTIR studies of chitosan acetate based polymer electrolytes. Electrochim Acta 2003;48:993-9.

[26] Lawrie G, Keen I, Drew B, Chandler-Temple A, Rintoul L, Fredericks P, et al Interactions between alginate and chitosan biopolymers characterized using FTIR and XPS. Biomacromolecules 2007;8:2533-41.

[27] Amaral IF, Granja PL, Barbosa MA. Chemical modification of chitosan by phosphorylation: an XPS, FT-IR and SEM study. J Biomat Sci-Polym E 2005;16: 1575-93.

[28] Bradbury T, Fehring TK, Taunton M, Hanssen A, Azzam K, Parvizi J, et al. The fate of acute methicillin-resistant Staphylococcus aureus periprosthetic knee infections treated by open debridement and retention of components. J Arthroplasty 2009;24:101-4.

[29] Welling MM, Brouwer CP, van 't Hof W, Veerman EC, Amerongen AV. Histatinderived monomeric and dimeric synthetic peptides show strong bactericidal activity towards multidrug-resistant Staphylococcus aureus in vivo. Antimicrob Agents Chemother 2007;51:3416-9.

[30] Elving GJ, van der Mei HC, Busscher HJ, van Nieuw Amerongen A Veerman EC, van Weissenbruch R, et al. Antimicrobial activity of synthetic salivary peptides against voice prosthetic microorganisms. Laryngoscope 2000;110:321-4

[31] Han X, Soblosky L, Slutsky M, Mello CM, Chen Z. Solvent effect and timedependent behavior of C-terminus-cysteine-modified cecropin P1 chemically immobilized on a polymer surface. Langmuir 2011;27:7042-51.

[32] Williams TJ, Schneider RP, Willcox MD. The effect of protein-coated contact lenses on the adhesion and viability of gram negative bacteria. Curr Eye Res 2003;27:227-35.

[33] Chen RX, Willcox MDP, Cole N, Ho KKK, Rasul R, Denman JA, et al. Characterization of chemoselective surface attachment of the cationic peptide melimine and its effects on antimicrobial activity. Acta Biomater 2012;8: 4371-9.

[34] Hilpert K, Elliott M, Jenssen H, Kindrachuk J, Fjell CD, Korner J, et al. Screening and characterization of surface-tethered cationic peptides for antimicrobia activity. Chem Biol 2009;16:58-69.

[35] Bagheri M, Beyermann M, Dathe M. Immobilization reduces the activity of surface-bound cationic antimicrobial peptides with no influence upon the activity spectrum. Antimicrob Agents Chemother 2009;53:1132-41.

[36] Bagheri M, Beyermann M, Dathe M. Mode of action of cationic antimicrobial peptides defines the tethering position and the efficacy of biocidal surfaces. Bioconjugate Chem 2012;23:66-74.

[37] Gao G, Cheng JTJ, Kindrachuk J, Hancock REW, Straus SK, Kizhakkedathu JN. Biomembrane interactions reveal the mechanism of action of surfaceimmobilized host defense IDR-1010 peptide. Chem Biol 2012;19:199-209. 